\section{Factors Associated with Survival of Burned Patients}

\title{
Abstract
}

Background: It is scarce in the literature studies regarding treatment and objective analysis of the survival chances of burned patients. Some investigations indicates the need for obtaining specific data to the population studied and characteristics such as social condition and nutritional status are suggested to be relevant to the patient's evolution. We aimed to describe the mortality of a Treatment Center Burn Unit (BU) in Brazil.

Methods: We analyzed 76 burned victims hospitalized with a fatal outcome in the General Hospital of São Matheus in 10 years (19992009). The following collected data were investigated were: age, sex, period of permanence, body surface burned (BSB), degree of burns, the causal agent, inhalation injury, nature of the event, clinical complications, mortality and survival rates.

Results: We observed predominantly male and the median age was 44 years old. The highest incidence was on June. The mean body surface area burned was 40\%, and upper limbs, the most affected region. The causative agents involved were more flammable agents and fire. Pulmonary infection was the most frequent clinical complication. The mortality found in this center was $4.9 \%$. The subgroup of suicide were predominantly female and the mortality rate was $22.44 \%$. When studying survival rate, patients with inhalation injury and trauma were associated with shorter survival. Patients with sepsis remained alive for longer.

Conclusion: The clinical, epidemiological and survival of patients with burns, enables the design of peculiar characteristics of this trauma in the studied area, thus, from these data, charts be established treatment and prognostic estimates, and assist in developing preventive public health policy more effective.

Sidney Zanasi ${ }^{*}$, Luiz Carlos de Abreu1,3, Thais Heinke ${ }^{4}$, Gerson V. Pereira Filho1, Fernando Adami ${ }^{1}$, Vitor E. Valenti1,2, Renata Salatini ${ }^{1}$, Italla Maria Pinheiro Bezerra1, Marco Akerman ${ }^{3}$

1 Laboratory Design and Scientific Writing Department of Community Health, $A B C$ Medical School. Av Principe de Gales, 821, 09060-650. Santo André, SP, Brazil.

2 Post-graduate Program of Physiotherapy, School of Sciences and Technology, UNESP. Rua Roberto Simonsen, 305. 19060-900 Presidente Prudente, SP, Brazil.

3 Public Health School, University of São Paulo, São Paulo, SP, Brazil.

4 Department of Pathology, UNIFESP/EPM, São Paulo, SP, Brazil.

Contact information:

Luiz Carlos de Abreu.

झ luiz.abreu@fmabc.br

Keywords

Burns, Mortality, Epidemiology, Suicide. 


\section{Background}

In the last two decades, remarkable advances in survival chances of burned patients have been obtained, especially in centers specialized in treating this type of trauma $[1,2]$.

The scientific findings leave less and less room for intuition with regard to treatment and objective analysis of the chances of survival in these patients. However, while the international literature pursues reproducible data also indicates the necessity of obtaining data specific to the population studied, since peculiarities such as nutritional status and social condition show is extremely important in the evolution of those rooms [1].

Burns should not be considered a fortuitous event, but a result of economic, human and social characteristics with other universal and peculiar from each population. In developing countries such as Brazil, it is imperative to establish objective data point to exactly which patient needs specialized care, as there is increased survival when treatments are based on individual scores, since the intensive care today not only prolong life but also enable more patients to be saved and survive with fewer sequels [2].

Moreover, the predictive data of survival may help in creating prevention programs, given the high cost of hospital treatment of these patients $[3,4]$. Therefore, we aimed to describe the clinical and epidemiological characteristics of burned patients.

\section{Methods}

This is a retrospective cohort study of 10 years, from January 1999 to December 2009, at Burns Treatment Centre (BTC) in São Paulo. Among a total of 1564 burned victims hospitalized in the period analyzed from medical records we considered only patients that died. The following variables were collected: age, sex, length of stay, body surface burned (BSB), degree of burn, causal agent, presence of inhalation injury, nature of the event, clinical complications, mortality and survival rates. The assessment of the databases was freely available. All procedures performed in the study were approved by the Ethical Committee in Research of the Faculdade de Medicina do $A B C$.

For quantitative variables descriptive statistics was performed using 25 percentile, median and 75th percentiles, since there were no parametric distribution (Shapiro-Wilk test: $p<0.05$ ) for qualitative variables we exposed through proportion. For the association between independent variables and time to death we applied univariate Cox regression. All independent variables were investigated and the proportionality guaranteed. It was adopted as the level of significance set at $p<0.05$. We used the statistical program Stata 11.0.

\section{Results}

Among the total hospitalized cases, we analyzed 76 individuals that died due to burn, resulting in a mortality of $4.9 \%$ relative to the 10 -year study (January 1999 to December 2009). The study group had a predominance of adults, aged between 20 and 59 years old (65.7\%), highlighting the number of children up to 9 years (5.2\%) and adolescents (10.5\%) (Table 1).

Table 2 shows the central tendency and dispersion for the study variables. Regarding the length of hospitalization, the median was 9 days, showing that the acute (first 24 hours) was overcome. In relation to the burned body surface area, the median values denote major burns according to the classification of the Ministry of Health of Brazil (Brazil's Ministry of Health, 2000).

We noted that the burns occurred mainly on the arms, forearms and hands (88.1\%), the region of the head and neck (82.8\%), chest (82.8\%) and lower limbs (64.4\%). The most common clinical complication was pulmonary infection (64.5\%) (Table 3). 
Table 1. Distribution of individuals with burns that died by age group. São Paulo, Brazil, 19992009.

\begin{tabular}{|l|c|c|}
\hline \multicolumn{1}{|c|}{ Age Group } & $\mathbf{N}$ & $\%$ \\
\hline $0-4$ & 2 & 2.6 \\
\hline $5-9$ & 2 & 2.6 \\
\hline $10-19$ & 8 & 10.5 \\
\hline $20-29$ & 9 & 11.8 \\
\hline $30-39$ & 9 & 11.8 \\
\hline $40-49$ & 19 & 25.0 \\
\hline 50 a 59 & 13 & 17.1 \\
\hline $60-69$ & 7 & 9.2 \\
\hline $70-79$ & 2 & 2.6 \\
\hline $80-89$ & 5 & 6.5 \\
\hline Total & 76 & 100.0 \\
\hline n=number of patients & & \\
\hline
\end{tabular}

Table 2. Central tendency and dispersion for the study variables of burn patients who died. São Paulo, Brazil, 1999-2009.

\begin{tabular}{|c|c|c|}
\hline Variables & Median (P25 - P75)* & Min - Max \\
\hline Age (years) & $44(30-54)$ & $1-88$ \\
\hline Length stays (days) & $9(3-30)$ & $1-111$ \\
\hline $\begin{array}{l}\text { Burned body } \\
\text { surface ares (\%) }\end{array}$ & $40.0(27.5-60.0)$ & $4-95$ \\
\hline $\begin{array}{l}\text { Body surface } \\
\text { burned 3rd degree } \\
(\%)\end{array}$ & $15(7-30)$ & $0-70$ \\
\hline
\end{tabular}

Table 3. Distribution of individuals with burns that died seconds anatomical regions affected and complication. São Paulo, Brazil, 19992009.

\begin{tabular}{|l|c|c|}
\hline \multicolumn{1}{|c|}{ Variables } & n & BSB $\%$ \\
\hline Anatomical regions affected & & \\
\hline Upper limbs & 67 & 88.1 \\
\hline Head and neak & 63 & 82.8 \\
\hline Chest & 63 & 82.8 \\
\hline Lower limbs & 49 & 64.4 \\
\hline Abdomen & 28 & 36.8 \\
\hline Perineum & 15 & 19.7 \\
\hline Clinical Complication & & \\
\hline Pneumonia & 49 & 64.5 \\
\hline Renal & 42 & 52.3 \\
\hline Sepsis & 29 & 38.2 \\
\hline n= number of patients & BSB\% percentage of body \\
\hline
\end{tabular}

The variables age, sex, etiologic agent, nature of the event, comorbidity, pulmonary and renal complications showed no statistically significant association with time to death, denoting that it does not interfere with the prognosis of the burn. On the other hand, patients with inhalation injury and trauma associated showed less time to death, indicating poor survival. Hazard ratio values were respectively 3.30 and 1.69. Patients who developed sepsis had better survival (hazard ratio $=0.24$ ) when compared to patients without generalized infection (Table 4).

Table 4. Number of patients that died, median survival, hazard ratio, confidence interval of $95 \%$ and $p$ values for the independent variables second model univariate Cox regression São Paulo, Brazil, 1999-2009.

\begin{tabular}{|l|c|c|c|c|}
\hline \multicolumn{1}{|c|}{ Dependents variables } & $\begin{array}{c}\text { Number of patients } \\
(\mathbf{\%})\end{array}$ & $\begin{array}{c}\text { Median time of survival } \\
\text { (days) }\end{array}$ & HR (CI95\%) & p \\
\hline Age (years) & & & 1 & \\
\hline$<20$ & $11(14.5)$ & 5 & $1.35(0.69-2.62)$ & 0.381 \\
\hline $20-60$ & $49(64.5)$ & 14 & $0.91(0.41-1.99)$ & 0.811 \\
\hline 60 or more & $16(21.1)$ & & 9
\end{tabular}




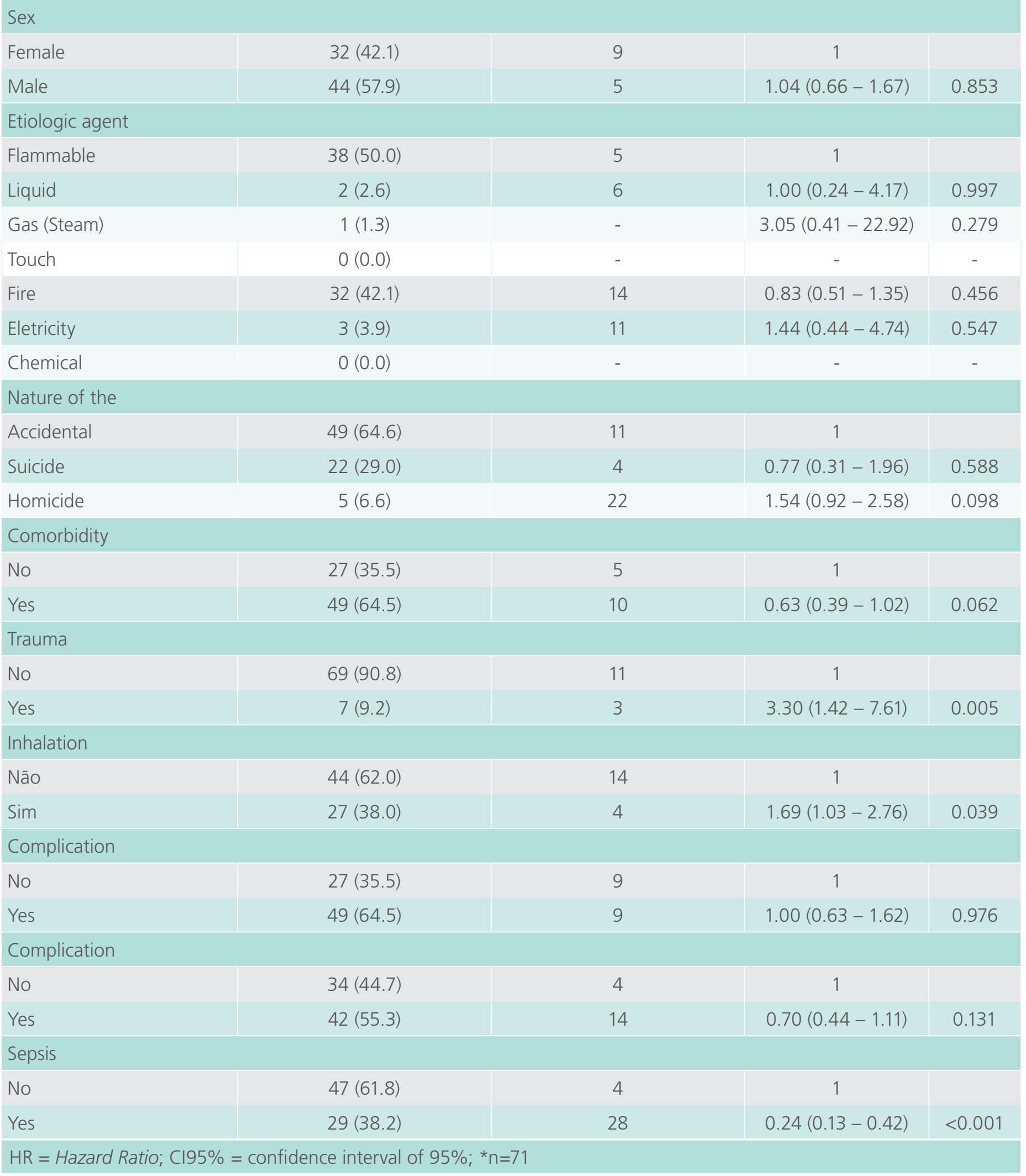


Figure 1 shows the survival of patients according to the variables that were statistically significant.

Figure 1: Graphs Kaplan_Meyer for independent variables that were significant in the univariate Cox São Paulo, Brazil, 1999-2009.

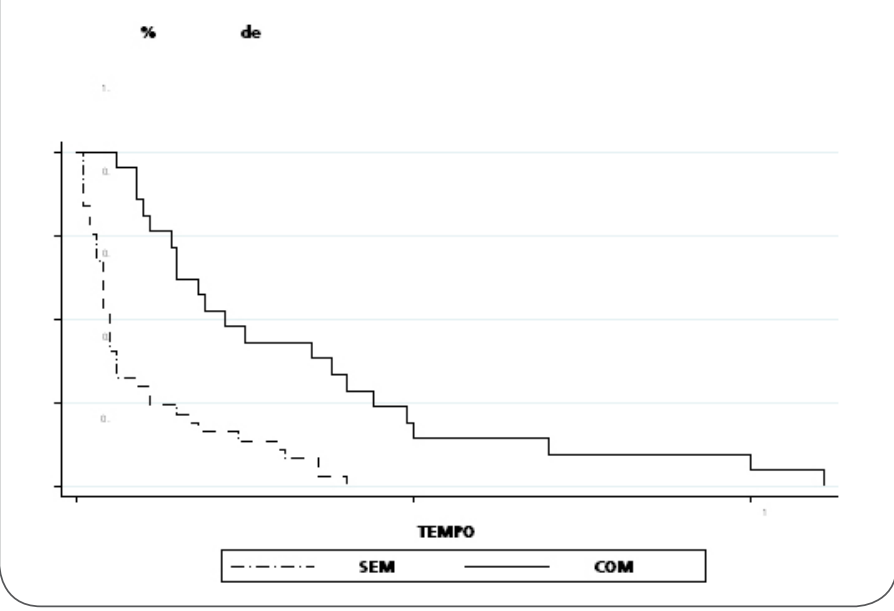

\section{Discussion}

Burn trauma is universal, it should be studied particularly in every treatment center in an attempt to provide patients with the specific behaviors to population that is inserted in a social, economic and cultural context. Based on our study, survival rate study and mortality associated factors may be established to help treatment and prognostic estimative.

Age is a primary factor determining death in burns $[8,12]$. Santi et al. states that age is also a major determinant of patient prognosis [13]. It is well established in the literature that death possibility at the extremes of age (children and elderly) are higher [14, 15]. On the other hand, others have found bimodal presentation different in age, with the first peak at six years old and second peak among young adults, differing from the bimodal distribution of the age extremes [12, 16-18]. In this study, the first peak occured in patients between 41 and 50 years old (25\%) and the second peak in the group between 51 and 60 years old (17.1\%), while the distribution converges with other works. The median age value was 44 years old (30-54 years old). Most patients $(65.7 \%)$ was in the age group between 21 to 60 years old, active portion of the population on the workforce.

According to DATASUS 2008 data [19], the highest death rate was found in patients aged 60 years old or older. In other studies with patients over 50 years old it was found a higher probability of mortality [15]. Olaitan et al. [20] found in their group patients older than 60 years old that presented a higher risk of death. Furthermore, they also found increased survival in the group of 0 to 10 years old, compared with the group of 71 to 80 years old. Age is one of the predictors of complications in burns $[7,8,15,20,21]$. In disagreement with the data cited $[7,8,15,20,21]$, in the results there was no predominance of age on survival.

With regard to gender, the study group was predominantly male $(57.9 \%)$ compared to females $(42.1 \%)$, both with similar survival. Williams et al. in 2009 also found no survivors in the group, the greater predominance were men (72\%) [5]. However, some authors [6] indicated that there may be influence of estradiol on immune function, cardiovascular and hepatocellular in women at higher risk of death [6].

Souza et al. (2002) [7] found a predominance of death in women compared to men. Both studies of Wolf et al. as of Ryan et al., found no relationship between gender and mortality, a similar fact verified in our series $[8,9]$. The studies of Muller et al. and George et al. found higher mortality in women over 60 years old $[10,11]$. Mortality related to sex depends heavily on the group and location studied variable to be further studied [11].

With respect to length of hospitalization, we found values of median of 9 days (3-30) with a minimum of 1 day and maximum of 111 days of hospitalization.

Regarding the location of the burn, the upper limbs were the most affected (88.1\%), followed by the head, neck and chest. As for body surface area 
burned, we observed median values of 40\% (27.5$60 \%)$, i.e. the patients studied had large burns, according to the classification of the Brazilian Ministry of Health (2000). The third degree burns were considered too large (greater than 10\% BSB), since it presented values of median of $15 \%$.

The causative agent is one of the factors associated with severity of trauma [7]. It may vary according to the region being studied, which may have different characteristics even within the same city. Agents are more involved alcohol, cigarette, use of stoves, hot water and electricity [24]. In this study we reported predominance of flammable and fire as causal agents. However, it was reported only 3.94\% male patients involved with electrical burns.

With respect to liquid (scald), we noted only $2.63 \%$ of accidents with this agent. The study population presented only $5.2 \%$ of patients aged 0 to 10 years old, which explains the low prevalence of this agent that is very common in Brazil. In this study, there were no deaths due to chemical burn type. Regarding the survival according to the agent, there was no statistical difference.

After the first time the hemodynamic and respiratory care are priorities, the next concern is infection control. This may account for 75 to $80 \%$ of deaths [26-28]. The most common sites of infection are: bloodstream, lungs, urinary tract and burned area [29]. Data from the American Burn Association (2008) [28] showed that among the 13,666 studied cases 10 major complications were related to infection, pneumonia was considered the most common. Several factors favor the infectious complications, such as the destruction of the cutaneous tegument, immunosuppression, bacterial translocation, the invasive diagnostic and therapeutic procedures, the inappropriate use of antibiotics and even prolonged hospitalizations. In the patients studied, the most common clinical complication was pulmonary infection in $64.47 \%$ followed by $52.26 \%$ in kidney failure and lastly sepsis with $38.15 \%$.
The reduction and inactivation of pulmonary surfactant have been reported as a result of this aggression in the airways [30]. Additionally, we have decreased mucociliary clearance and subsequent increased vulnerability to infection sites and bronchospasm. The data found on complications differ from some studies reviewed. Macedo and Saints (2006) [27] reported $30.9 \%$ of cases with infection, and $20.5 \%$ from the bloodstream, $17.6 \%$ of the burned area and $6.5 \%$ in the lungs. D'Avignon et al. (2010) [28] was the main cause of death in 50\% systemic infection, followed by pneumonia and infection of the area burned. Not all of the signs and symptoms of airway injury are perceptible to the examiner, there is a high incidence of false-positive values. Although $70 \%$ of patients with inhalation injuries were burned on the face, $70 \%$ of patients with burned face show no significant lesions of the lower tract [31]. Anatomical abnormalities seen on bronchoscopy precede changes in gas exchange and radiographic changes. Therefore, it highlights the importance of early bronchoscopy assessment in all patients with clinical suspicion of inhalation injury [32]. This method has the highest sensitivity and specificity when compared to the gold standard, which is the histopathological analysis of a fragment of the bronchial mucosa [31]. In this study, in terms of survival, there was higher risk of death in patients with inhalation injury (hazard ratio of 1.69) compared to those who had not inhaled smoke.

Regarding the site of infection, the study of Taran et al. [33] investigated the necropsies of 186 burned patients, $64.2 \%$ presented a destructive process in the pulmonary system and pneumonia was reported in $82 \%$ of cases [33]. Another study that confirms these findings and Taran et al. [33], is the largest conducted in the burn unit of the U.S. Army, where $55 \%$ of deaths from burns detected the presence of pneumonia [34]. Along with the $\mathrm{BSB}$, lesion depth and age, lung lesions also interfere with the patient's prognosis. [31] The association between inhalation injury and pneumonia may in- 
crease mortality by $60 \%$ [35]. The difference of the results shows that each BTC must know the clinical and epidemiological profile of patients treated in that locality. This is reinforced when we look at the median time of survival and found that pulmonary complications and comorbidities did not influence our patients.

The second most frequent clinical complication was acute renal failure (52.26\%). Renal changes in burned patients vary between 1 and 36\% depending on the population studied and the criteria used for diagnosis. The phase of resuscitation is the most common cause of death, this can result in failure of other organs [36]. Acute renal failure had no influence on patient survival according to our data.

Bloodstream infection in burned patients occurs after breaking the skin barrier and the consequent invasion of pathogens via lymphatic and/or blood, thus, determining sepsis. Generally, gram-positive bacteria that inhabit the hair follicles and sebaceous glands deeper, can survive the injury, colonizing the surface within 48 hours. Another carrier of infection is venipunctures. This whole set of factors predisposes the progression from simple colonization to infection in the burned area and later systemic infection [28].

In this study $38.15 \%$ of patients had signs and symptoms of generalized infection. The invaders in burned patients may be bacteria, viruses or fungi, each burn unit should periodically determine their most prevalent pathogens. Macedo et al. (2005) [37] also cited as a risk factor for sepsis in ascending order, using three or more catheters, presence of two or more clinical complications, BSB greater than or equal to $30 \%$, open flame as agent and females. As for survival, those with signs of generalized infection survived 0.24 times more than those who did not have this complication. Probably these patients exceeded the acute complications, staying longer in intensive clinical treatment.

Converging with our data is the work of Williams et al. (2009) [37] who obtained 43 days of hospita- lization in patients with sepsis on average, 26 days in patients with respiratory disorders and 7 days in patients presenting with cardiogenic shock secondary to hypovolemia, showing that depending on the course and characteristics of trauma we may have changes in survival time [5].

Regarding the nature of the event 49 (64.47\%) were burned accidentally, 22 (28.94\%) due to suicide and 5 (6.57\%) homicide victims. In this study we had 22 cases of death due to suicide. In these cases usually it is observed the highest percentages of burned areas and the low compliance with treatment by virtue of their own psychological depression often associated framework. In this group the prevalence of depression is greater than the normal population [38, 39]. In Brazil, due to the ease of acquisition of liquid alcohol, not observed in other countries it is very common for suicide attempts to be made by women using this agent, with a higher mortality rate in these cases [14, 22]. At work 17 patients (77.3\%) used agent-flammable and 5 $(22.7 \%)$ directly used fire to commit suicide. The most common mechanism occurs generally kindled by the flammable liquid that was poured over the body, in an attempt to consummate suicide. That is problem in public health $[40,41]$.

The patients presented lower trauma associated with time to death, indicating worse survival by 3.3 times compared with those patients who had only the burn.

As stated, the burned patient has unique characteristics both clinical, epidemiological and how survival is influenced by many factors. It is imperative that each center specializing in this type of disease, study and learn about the population profile of your surroundings so that the processing is carried out as accurately as possible, and these data can directly influence the campaigns of prevention and resource management of this disease that affects our body and physical scars, mental and emotional. 


\section{Conclusions}

The hospital mortality in our study was 4.9\%. The patients were mostly adults with major burns affecting predominantly the upper limbs, head and neck region. The median hospitalization period was 9 days. Pneumonia was the most common clinical complication. Age, sex, etiologic agent, nature of the event, comorbidity, and pulmonary complication had no effect on patient survival. Patients with sepsis had higher survival.

\section{Acknowledgements}

This research received financial support from Faculdade de Medicina do ABC.

\section{Conflict interests}

The authors declare that they have no conflict interests.

\section{Authors' contributions}

All authors participated in the acquisition of data and revision of the manuscript. All authors determined the design, interpreted the data and drafted the manuscript. All authors read and gave final approval for the version submitted for publication.

\section{References}

1. Crisostomo MR, Serra MCVF, Gomes DR. Tratado de Queimaduras. São Paulo: Atheneu; 2004.

2. Gomes DR, Serra MC, Pellon MA. Queimados. Rio de Janeiro: Revinter; 1995.

3. Telerman R. Burns: characteristics of patients treated at the General Hospital of St. Matthew, São Paulo [Dissertação de Mestrado]. São Paulo: Escola Paulista de Medicina, Curso de Medicina, Departamento de Cirurgia Plástica, 1999.

4. McGwin G, George RL, Cross JM, Reiff DA, Chaudry IH, Rue LW. Gender differences in mortality following burn injury. Shock 2002; 18: 311-5.

5. Williams FN, Herndon DN, Hawkins HK, Lee JO, Cox RA, Kulp $\mathrm{GA}$. The leading causes of death after burn injury in a single pediatric burn center. Critical Care 2009; 13: 1-7.

6. Muller MJ, Pegg SP, Rule MR. Determinants of death following burn injury. Br J Surg 2001; 88: 583-7.

7. De Souza DA, Manço ARX, Marchesan WG, Greene LJ. Epidemiological data of patients hospitalized with Burns and other traumas in some cities in southeast of Brazil from 1991 to 1997. Burns 2002; 28: 107-14.

8. Wolf SE, Rose JK, Desai MH, Mileski JP, Barrow RE, Herndon DN. Mortality determinants in massive pediatric burns. Ann Surg 1997; 225: 554-69.

9. Ryan CM, Schoenfeld DA, Thorpe WP, Sheridan RL, Cassem EH, Tompkins RG. Objective estimates of probability of death from burn injuries. New Engl J Med 1998; 338: 362-66.

10. Muller MJ, Pegg SP, Rule MR. Determinants of death following burn injury. Br J Surg 2001; 88: 583-7.

11. George RL, McGwin Jr G, Schwacha MG, Metzger J, Cross JM, Chaundry $\mathrm{IH}$. The association between sex and mortality among burn patients as modified by age. J Burn Care Rehabil 2005; 26: 416-21.

12. Williams FN, Herndon DN, Hawkins HK, Lee JO, Cox RA, Kulp $G A$. The leading causes of death after burn injury in a single pediatric burn center. Critical Care 2009; 13: 1-7.

13. De Santi L. Pathophysiology and current management. Adv Skin Wound Care. 2005; 18: 323-32.

14. De Macedo JLS, Rosa SC. Epidemiological study of patients admitted to the burn unit: Hospital Regional da Asa Norte, Brasília, 1992-1997. Brasília Med 2000; 37: 87-92.

15. De Macedo JLS, Santos JB. Predictive factors of mortality in burn patients. Rev Inst trop S. Paulo 2007; 49: 365-70.

16. McGwin Jr G, Cross JM, Ford JW, Rue LW. Long-term trends in mortality according to age among adult burn patients. J Burn Care Rehab 2003; 24: 21-25.

17. Oliveira KC, Penha CM, Macedo JM. Epidemiological profile of children burn victims. Arq Med ABC 2007; 32: 55-8.

18. Souza AA, Mattar CA, Almeida PCC, Faiwichow L, Fernandes FS, A. Neto EC, Manzotti MS, Paiva LGT. Epidemiological profile of patients admitted to the Burns Unit at the Hospital for State Civil Servants of São Paulo. Rev Bras Queim 2009; 8: 87-90. 
19. DATASUS [site na internet]: Brasil: Banco de dados do Sistema Único de Saúde Brasil. Ministério daSaúde/Funasa/CENEPI Sistema de Informações sobre Mortalidade - SIM, 1998. cited in november 2006. Acessed in: http://www.datasus.gov.br/cgi/ sim/dxmap.htm

20. Olaitan PB, Jiburum BC. Analysis of burn mortality in a burn centre. Ann Burn Fire Disasters 2006; 2: 1-5.

21. Rossi LA, Barruffini RCP, Garcia TR, Chianca TCM. Burns: characteristics of cases treated in a teaching hospital in Ribeirão Preto (SP), Brazil. Rev Panam Salud Publica/Pan Am J 1998; 4: 401-4.

22. Pereima MJL, Mignoni ISP, Bernz LM, Shweitzer CM, De Souza JA, De Araújo EJ: Analysis of the incidence and severity of alcohol burns in children from 2001 to 2006: impact of Resolution 46 Rev Bras Queimaduras 2009, 8: 51-9.

23. Barreto MGP, Bellaguarda EAL, Burlamaqui MPM, Barreto RP, Oliveira PRT, Lima Jr EM: Epidemiological study of burn patients in Fortaleza, Ceará: Review from 1997 to 2001. Rev Pediatr 2008; 9: 23-9.

24. Mock C, Peck M, Peden M, Krug E: eds. A WHO Plan for burn prevention and care. Geneva, World Health Organization 2008.

25. Prestes MA, Lopes Junior SLC. Severity of injury and indicators for hospitalization. In: Lima Junior EM, Novaes FN, Piccolo NS, Serra MCVF. Tratado de queimaduras no paciente agudo. $2^{\text {a }} \mathrm{Ed}$. São Paulo: Ed Atheneu; 2008.p49-52.

26. Leonardi DF, Chem RC, Furlian R. Histological assessment of burns of indeterminate depth as a predictor of healing time. Arqu Cat Med 2005; 34: 47-51.

27. De Macedo JLS, Santos JB. Infectious complications in burn patients. Rev Soc Bras Plást 2006; 21: 108-11.

28. D'Avignon LC, Hogan BK, Murray CK, Loo FL, Hospenhtal DR, Cancio LC. Contribution of bacterial and viral infections to attributable mortality in patients with severe burn: An autopsy series. Burns 2010; 36: 773-79.

29. Rafla K, Tredget EE. Infection control in burn unit. Burns 2011; 4: 5-15

30. Mlack RP, Suman OE, Herndon DN. Respiratory management of inhalation injury. Burns 2007; 33: 2-13.

31. Rabello E, Batista VF, Lago PM, Alvares RA, Martinusso CA, Lapa e Silva JR. Analysis of bronchoalveolar lavage fluid in victims of severe facial burns. J Bras Pneumol 2009; 35: 343-50.

32. Souza R, Jardim C, Salge JM, Carvalho CRR. Smoke inhalation injury. J Bras Pneumol 2004; 30: 557-65.

33. Taran A, Baciu N, Rafulea V, German A. Clinical and autopsy diagnoses of visceral affections of patients who died because of complicated burn with multi-organ failure. Ann Burns Fire Disasters 2005; 18: 2-13.

34. Church D, Elsayed S, Reid O, Winston B, Lindsay R. Burn wound Infections. Clin Microbiol Rev 2006; 6: 403-34.

35. Shirani KZ, Pruitt BA, Mason A. The influence of inhalation injury and pneumonia on burn mortality. Ann Surg 1987; 205: 82-7.
36. Steinvall I, Bak Z, Sjoberg F. Acute kidney injury is common, parallels organ dysfunction or failure, and carries appreciable mortality in patients with major burns: a prospective exploratory cohort study. Critical Care 2008; 12: 1-10.

37. De Macedo JLS, Rosa SC, De Macedo KCS, Castro C. Risk factors for sepsis in burned patients. Rev Col Bras Cir 2005; 32: 173-77.

38. Thombs BD, Bresnick MG. Mortality risk and lenth of stay associated with self-inflected burn injury: Evidence from a national sample of 30.382 adult patients. Crit Care Med 2008; 36: 118-25.

39. Palmu R, Suominen K, Vuola J, Isometsa E. Mental disorders among acute burn patients. Burn 2010; 36: 1072-79.

40. Atrash HK, Carpentier R. The evolving role of public health in the delivery of health care. J. Hum. Growth Dev. 2012; 22(3): 396-399

41. Monteiro CBM, Almeida Junior AD, Wajnzstejn R. Project Management in Health and Medical Research. J. Hum. Growth Dev. 2014; 24(3): 239-242. Doi: dx.doi.org/10.7322/jhdg.88895

\section{Comment on this article:}

\section{(f) 13 in $8+\mathbf{S} P$}

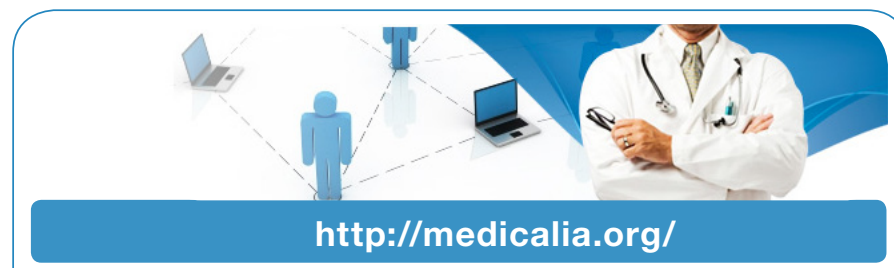

Where Doctors exchange clinical experiences, review their cases and share clinical knowledge. You can also access lots of medical publications for free. Join Now!

\section{Publish with iMedPub}

\section{http://www.imed.pub}

International Archives of Medicine is an open access journal publishing articles encompassing all aspects of medical science and clinical practice. IAM is considered a megajournal with independent sections on all areas of medicine. IAM is a really international journal with authors and board members from all around the world. The journal is widely indexed and classified Q1 in category Medicine. 